\title{
AS ESTRATÉGIAS DA RELAÇ̃̃O ESTADOS UNIDOS-COLÔMBIA E SEUS DESDOBRAMENTOS PARA A CORRELAÇÃO DE FORÇAS SUL-AMERICANAS
}

THE STRATEGIES OF THE UNITED STATES-COLOMBIA RELATIONSHIP AND ITS

DEVELOPMENTS FOR THE CORRELATION OF SOUTH AMERICAN FORCES

Gabriel Graziottin ${ }^{1}$

\section{RESUMO}

Esse estudo objetiva uma análise das estratégias do alinhamento Estados Unidos Colômbia e seus desdobramentos para a correlação de forças securitárias da América do Sul, a partir de 2000. Para tanto, buscam-se apresentar os condicionantes; os objetivos estratégicos e as potencialidades dessa relação para o desenvolvimento regional, à luz de algumas perspectivas já desenvolvidas em estudos anteriores.

Palavras-chave: Relações EUA-Colômbia; Estratégias; Correlação de forças sulamericanas.

\begin{abstract}
This work aim to analyses the United States-Colombia strategic alignment with its unfolding implications to the South American security correlation of forces, from 2000s. In order to achieve this goal, this paper will present the constraints; strategic goals and potentials of this relation in to the regional development in light of some views already developed in preview works.
\end{abstract}

Key words: USA - Colombia relations; Strategies; Correlation of South-American forces.

\section{INTRODUÇÃo}

Os Estados Unidos e a Colômbia desde o século XX tiveram uma relação muito próxima em suas trajetórias de desenvolvimento, acentuadamente no período recente após a efetivação do Plano Colômbia em 2000, acarretando desdobramentos para a região sul-americana e seu processo de desenvolvimento recente. Desse modo, no presente estudo propõe-se desenvolver uma análise estratégica da relação Estados Unidos-Colômbia, paralelo aos seus desdobramentos para a correlação de forças sulamericanas, à luz de condicionantes, potencialidades e objetivos.

\footnotetext{
${ }^{1}$ Mestrando em Ciência Política da Universidade Federal do Rio Grande do Sul (UFRGS)
} 
Com isso, objetiva-se trazer algumas contribuições, desenvolver debates e apresentar perspectivas analíticas já desenvolvidas dessa relação para os desdobramentos regionais da América do Sul, destacando-se os condicionantes históricos, securitários, político-estratégicos e econômicos subjacentes à cooperação Washington - Bogotá. Para isso, se empreenderá uma leitura estratégica, tanto da política externa estadunidense, como da política colombiana para a região sulamericana, sob o método hipotético-dedutivo, uma vez que se aceita a ideia de relativa reconfiguração da correlação de forças sul-americanas por meio dessa relação. A perspectiva utilitarista viabilizada pelos pressupostos realistas será um instrumento de análise dessa relação.

De acordo com Gideon Rose (1998), distinguindo-se das demais leituras realistas que advogam a busca ininterrupta dos Estados pela segurança, a corrente realista neoclássica defende que os Estados respondem às incertezas do sistema internacional, procurando modelar e controlar o seu ambiente externo. Assim, os Estados geralmente almejam maiores influências externas, perseguindo essa ambição até quando são capazes. Entretanto, é necessária a compreensão de como as pressões sistêmicas são traduzidas para níveis unitários, tais quais variáveis domésticas; a percepção dos formuladores de decisões políticas; elites e a estrutura estatal, em uma dinâmica interméstica que restringe e impulsiona a política externa dos Estados. Dessa forma, se utilizará essa corrente do Realismo por ser mais sensível às variantes intermésticas, elites políticas e tomadores de decisões, característicos das variantes que compõem os sistemas de governança securitária sul-americana e as prerrogativas estratégicas colombo-estadunidenses. Ao mesmo tempo, que não se negará a influência das condições sistêmicas, assimetrias de poder entre os Estados e as formas de competição/cooperação entre eles.

\section{CONDICIONANTES HITÓRICOS DA RELAÇÃO EUA-COLÔMBIA ATÉ O PERÍODO RECENTE}

A Colômbia situa-se ao norte da América do Sul, integrando-se o eixo dos países andinos. Possui acesso ao Mar do Caribe e ao Oceano Pacífico e grande parte de seu 
território integra a Floresta Amazônica. ${ }^{2}$ Por suas peculiaridades geopolíticas, papel periférico de inserção internacional, conflitos sociais internos e a direção política promovida por suas elites, a Colômbia sempre desenvolveu uma relação muito próxima com Estados Unidos, passando a inserir-se à sua órbita hegemônica hemisférica. ${ }^{3}$

Os condicionantes históricos das relações da Colômbia para com os Estados Unidos são descritas por Santos (2010) da seguinte maneira:

Seja por pragmatismo, convicção ou conveniência das elites políticas e econômicas do país, ou por sugestões, intervenções ou imposições dos EUA, o fato é que, desde a perda do Panamá, no início do século XX, a Colômbia tem uma relação muito próxima aos norte-americanos. Um capítulo fundamental dessa história está sintetizado na formulação da doutrina Respice Polum, que teve início no governo de Marco Fidel Suarez (1918-1922) e predominou na diplomacia colombiana ao longo do século XX. Segundo essa doutrina, o país deveria adotar um alinhamento incondicional às diretrizes dos EUA em matéria de política externa, sob a convicção de que, além de pertencer à esfera de influência da "estrela polar do norte", a Colômbia poderia tirar grande proveito dessa associação. (SANTOS, 2010, p. 68, grifo do autor)

Desse modo, percebe-se que um "pacto" foi historicamente firmado entre os dirigentes colombianos a um alinhamento incondicional às diretrizes políticas norteamericanas, transpondo relações pragmáticas, conveniências, intervenções e imposições de um país fatalizado por pertencer ao lócus de influência dos EUA. Reforçando esses condicionantes, existem as reais demandas do país andino para com o parceiro do norte:

Colombia has been at war with the FARC, drug cartels and various criminal gangs since 1964, when the FARC began South America's longestrunning insurgency. In the 1970s and 1980s, Colombia emerged as the world's largest cocaine producer. This trade created powerful drug cartels whose influence and violence threatened the viability of the state as a whole. The United States has provided aid to the government of Colombia for several decades. Through the last decade of U.S. support, in particular Colombian military and law enforcement institutions have grown in proficiency and sophistication. (KILLEBREW; IRVINE; GLASER, 2012, p. 237-8)

Assim, o Estado jamais no período recente conseguiu consolidar o seu poder frente ao constante conflito armado perpetuado em seu território, seja pela disputa

${ }^{2}$ Fonte: IBGE Países. Disponível em: http://www.ibge.gov.br/paisesat/main frameset.php 
entre os cartéis narcoprodutores ou por grupos guerrilheiros paramilitares que ocupam importantes territórios.

[...] el país estaba bajo la amenaza del poder corruptor de los carteles de la droga que había intentado instaurar una "narcodemocracia"2; por su parte, la agudización del confl icto había suscitado el desplazamiento forzado de millones de personas y el aumento en el número de homicidios y masacres por lo cual Colombia califi caba como una crisis humanitaria que requería de atención urgente; algunos otros avanzaron sobre la hipótesis de un "estado cuasi fallido" o en riesgo de colapsar ante la precariedad institucional y la pérdida de control territorial y la crisis de legitimidad. (ROJAS, 2009, p. 112).

É perceptível a quase falência do Estado colombiano durante os anos 1990 através do intenso conflito dos distintos atores nacionais e as repercussões para sua desestruturação social. Estratégias de guerras, deslocamentos forçados, massacres, sequestros e atentados marcaram essa fase do país. Somava-se a esse bojo o risco iminente de uma desestabilização regional promovida por uma "narco-democracia" controlada por cartéis de drogas, catalizando a atenção dos países vizinhos e dos Estados Unidos.

Governo Pestrana (1998-2002) formula, com isso, a estratégia de internacionalização do conflito que o seu país enfrentava, recorrendo a uma intervenção internacional. 0 objetivo era claro: recuperar o poder do Estado colombiano através da militarização contra a poderosa rede narcoprodutora nacional e grupos beligerantes antagônicos. Os Estados Unidos, desse modo, continuariam como um importantíssimo parceiro. 0 Plan Colombia, dessa forma, tornou-se a solução para esse dilema.

In July 2000, US President, Bill Clinton, signed into law the aid package popularly known as 'Plan Colombia', the US government's contribution to a Colombian counternarcotics and development plan. The policy would commit approximately $\$ 1.6$ billion dollars in US financial and military assistance to the Colombian government (with a small part for its Andean neighbors) to primarily strengthen Colombia's military capabilities and effectiveness against a guerrilla insurgency. (AVILÉS , 2008, p. 410) ${ }^{4}$

O Plano Colômbia reveste-se como a mais importante cooperação entre Washington e Bogotá nesses últimos quinze anos. Os objetivos, conforme Avilés, (2008) são: o fortalecimento da estrutura militar colombiana, permitindo não só o

\footnotetext{
${ }^{4}$ Inicialmente o valor estipulado de auxílio à Colômbia era de 1,6 bilhão de dólar, durante seis anos, visando a redução da produção de cocaína. Porém, entre 2000 e 2012, os EUA gastaram mais de 8 bilhões de dólares com o Plano Colômbia e iniciativas relacionadas. (Bureau of Western Hemisphere Affairs, 2012).
} 
desmoronamento institucional do Estado frente aos conflitos sociais que enfrentava, como a retomada de uma ofensiva contra os grupos insurgentes, recuperando, dessa forma, posições estratégicas de seu território. ${ }^{5}$

Um novo "pacto", com isso, foi firmado entre Bogotá e Washington via uma “intervenção à convite", reforçando a tradição colombiana de incorporação nacional à política externa estadunidense. Entretanto, é necessário destacar que essa cooperação recente não fora desigual para nenhum desses atores, apesar de suas assimetrias. Os ganhos foram frutificados pelos dois lados em uma relação pragmática, a despeito da condição do Estado colombiano como um protetorado estadunidense no limiar do século XXI.

\section{A COOPERAÇÃO COLOMBIANA: OBJETIVOS, BENEFÍCIOS E POTENCIALIDADES PARA OS ESTADOS UNIDOS}

As relações entre Bogotá e Washington corresponderam a diversas necessidades decorrentes da fragilidade do Estado colombiano em seu desenvolvimento recente. Porém, essa cooperação também correspondeu a muitos interesses estadunidenses no território sul-americano, especialmente à luz de mudanças regionais recentes dos anos 2000 em diante. Desse modo, faz-se necessário analisar as potencialidades, recursos e objetivos visados pelos EUA nessa parceria, transcendendo o amparo a um convulsionado Estado narcoprodutor.

A Colômbia e o espaço sul-americano, como um todo, sempre possuíram grande relevância estratégica para os Estados Unidos em sua hegemonia hemisférica. Vastas reservas energéticas, economias nacionais em desenvolvimento e recursos de projeção

\footnotetext{
5 Segundo o Executivo colombiano, o Plano Colômbia destinava-se a ser um "plano para a paz, prosperidade e fortalecimento do Estado", destinando cerca de $76 \%$ de seus recursos provenientes de crédito externo ao investimento social, e o restante direcionado ao combate ao narcotráfico como uma das prioridades do governo. Inicialmente, a iniciativa norte-americana foi projetada como um mecanismo militar de combate à produção e ao tráfico de drogas ilegais na Colômbia e em outros países da região andina.

A proposta, de 7,5 bilhões de dólares, apresenta três componentes: primeiro, a aproximação do Estado colombiano com as populações afetadas pela violência por meio de investimentos sociais e substituição de plantios de coca, devendo o governo disponibilizar 4 bilhões de dólares para esse fim; segundo, assistência técnica, militar e financeira dos EUA, no montante de 1,3 bilhão de dólares, para o combate ao narcotráfico em toda região andina, especialmente na Colômbia. Desses recursos, cerca de $55 \%$ foram dirigidos às forças armadas e $27 \%$ à polícia, enquanto que os projetos de desenvolvimento alternativo obtiveram somente $9 \%$ dos recursos, assistência a deslocados, $3 \%$, reforma judicial, $2 \%$, proteção de direitos humanos, $1 \%$, e recursos para a paz, menos de 1\% (VILLA; OSTOS, 2005, p. 9).
} 
de poder correspondem à importância da preservação do subcontinente à região de influência dos EUA. Entretanto, o cenário sul-americano se reconfigurou no final dos anos 1990 em função do quadro de crises econômicas, desigualdades sociais via políticas neoliberais fomentadas por Washington nos anos 1990.

De acordo com Bandeira (2008), os Estados Unidos tiveram um visível declínio de sua influência na América do Sul, decorrente dos fracassos dessas políticas capitaneadas pelo Consenso de Washington (1989) atrelado ao surgimento de governos nacionalistas de esquerda, desvinculados diretamente aos interesses hegemônicos estadunidenses. O mapa político sul-americano redesenhou-se com a oposição protagonizada pela Venezuela de Chávez, reforçado com a eleição do Presidente Luiz Inácio Lula da Silva, no Brasil, Nestor Kirchner, na Argentina, Evo Morales, na Bolívia, Tabaré Vásquez, no Uruguai, e Rafael Correa, no Equador. Alguns mais radicais, outros mais moderados, exprimiram a rejeição ao domínio e influência dos Estados Unidos no subcontinente. Somado a isso, ocorreu o avanço de mecanismos de cooperação econômica e política entre os países sul-americanos, como o Mercado Comum do Sul (MERCOSUL) e o fracasso da iniciativa de Washington na criação da Área de Livre Comércio nas Américas (ALCA), englobando todos os países em sua órbita comercial. (COSTA, 2008) A UNASUL constituiu outro movimento regional de desenvolvimento político autônomo às pressões externas da região.

Desse modo, a Colômbia e alguns países sul-americanos que não se desalinharam aos interesses norte-americanos na região, à margem da maioria, permaneceram um importante meio de preservação da influência dos Estados Unidos no subcontinente, revestindo-se de uma maior relevância para uma cooperação política com Washington. ${ }^{6}$ As recentes transformações regionais sul-americanas paralelas aos conflitos enfrentados pelo Estado colombiano, desse modo, reforçaram o isolamento do país frente aos seus vizinhos, acrescido ao tradicional alinhamento à política externa da "estrela polar do norte" com o Plano Colômbia. Desse modo, coube aos EUA aproveitar essa oportunidade. ${ }^{7}$

\footnotetext{
6 Tal qual o Peru e o Chile, todos banhados pelo Oceano Pacífico e com um modelo econômico liberalizante, em compatibilidade com a economia estadunidense. (FLEMES; CASTRO, 2016)

${ }^{7}$ De acordo com Avilés (2008): "The success of this bloc in the Colombian case is relevant, as US policy, despite its unipolar position globally, has faced resistance to its drug war policies in Venezuela, Bolivia and most recently in Ecuador, in countries in which nationalist groupings have successfully resisted globalist sectors and have been able to wield power over their respective nation-states, disrupting their
} 


\section{Por trás da guerra ao narcotráfico: recursos e potencialidades mútuas}

A reaproximação entre Washington e Bogotá correspondeu com objetivos estratégicos estadunidenses, subjacentes à retórica oficial de guerra ao narcotráfico e a grupos insurgentes colombianos. A Colômbia deveria proporcionar as vantagens necessárias aos interesses político-securitários, econômicos e energéticos a potência do norte. Já os EUA, em contrapartida, também faziam parte do cálculo estratégico da Colômbia em seu alinhamento político.

Para Cantor (2012), as condições geográficas da Colômbia são extremamente favoráveis à projeção do poder militar estadunidense sobre o território sul-americano, por meio do acesso aos oceanos Atlântico e Pacífico e a capacidade de ofensiva militar a qualquer país do subcontinente. A Colômbia, desse modo, reforça a posição de controle dos EUA em seu entorno estratégico, abarcando não só o Mar Caribenho como toda a América do Sul. 8 As riquezas naturais são outro ponto relevante da Colômbia, constituindo-se de fontes de recursos energéticos aos EUA e a viabilidade do controle da Floresta Amazônica. Em um cenário de possível desdobramento de um conflito armado, o acesso aos recursos naturais da Amazônia favorece a posição norte-americana. Bandeira (2008) salienta essa ideia da seguinte maneira:

0 estacionamento permanente de tropas e equipamentos bélicos, no Suriname e na Guiana, bem como na Colômbia e também no Peru, 46 como antes no Equador e na Bolívia, dão aos Estados Unidos enorme vantagem estratégica, para intervir militarmente em qualquer país, se necessário, a fim de defender seus interesses econômicos e ocupar as nascentes do rio Amazonas. (2008, p. $25)^{9}$

Isto é, o acesso à Amazônia se viabiliza pela superioridade militar dos EUA na região dos Andes, através do acesso aos territórios colombo-peruanos. A Colômbia, por possuir um território incluso na Floresta Amazônica, potencializa os deslocamentos norte-americanos em projetos de ofensiva militar na região e o controle dos vastos

integration into US-led global capitalism". Verifica-se, dessa forma, a baixa influência política de Washington até para a região andina do sobcontinente, reforçando a necessidade de cooperação com a Colômbia.

8 Filho (2013) reforça esse argumento, assinalando as potencialidades estratégicas colombianas para o poder estadunidense. As bases navais, por exemplo, colocaram à disposição dos norte-americanos instalações no Pacífico e no mar das Caraíbas, aumentando consideravelmente a projeção militar naval do país no norte da América do Sul e no próprio Caribe. Já as bases do Exército apresentam também vantagens importantes para os Estados Unidos, haja vista que uma possui "grandes dimensões e uma pista que pode servir para aeronaves de transporte pesado", e a outra é a base avançada mais próxima da Amazônia. 
recursos amazônicos. 0 Brasil, que detém a maior proporção da Amazônia, irrefutavelmente teme uma possível perda de sua soberania por meio dos recursos dissuasórios empregados pelos estadunidenses na região em parceria com a Colômbia. Nesse sentido, as relações estreitas entre os EUA e a Colômbia constituem uma correlação de forças favorável à Washington na região sul-americana, sendo uma forma instrumentalista de contraposição aos interesses regionais antagônicos às suas formulações estratégicas.

0 acesso aos recursos energéticos colombianos soma-se como um dos principais fatores benéficos aos EUA em sua relação com o país andino, imiscuído na estratégia oficial da Guerra às Drogas. Para Bandeira (2008), cerca de onze das dezoito empresas que extraem petróleo na Colômbia são norte-americanas, cujos investimentos financiam a exploração de um terço do seu território. A descoberta de novas reservas torna-se essencial para as exportações, o que implica a pesquisa e lavra do petróleo em outro terço do país, controlado majoritariamente pelo Exército de Libertação Nacional (ELN), no norte, e pelas Forças Armadas Revolucionárias da Colômbia (FARC) ao sul. Desse modo, é incluído aos interesses norte-americanos o combate às FARC e o ELN decorrente do acesso a esses recursos energéticos, favorecendo paralelamente o Estado colombiano sobre o domínio efetivo de territórios nacionais ainda não controlados.

De acordo com Dawn Paley (2015, p. 115):

Violent attacks on Colombian energy installations, prior to and within the context of the post-11 September global anti-terrorism campaigns, have provided U.S. lawmakers and members of the executive branch with legitimating arguments for increasing military aid to Colombia and expanding significantly and without precedent, the U.S. mission there beyond counternarcotics to include counter-insurgency and counter-terrorism.

Assim, verifica-se que enquanto o Plano Colômbia falhou acerca da redução da produção de cocaína, a militarização da Colômbia contribui para a proteção e o crescimento da exploração de recursos naturais disponíveis pelas companhias multinacionais. ${ }^{10}$ Em contrapartida, ao se analisar o desenvolvimento da cooperação

10 Cantor (2012, p. 394) é mais taxativo ao destacar os ambiciosos interesses energéticos dos EUA no território sul-americano: "Por supuesto, no sólo está en la mira el petróleo de Venezuela sino que Estados Unidos también desea controlar y apoderarse de otros recursos naturales que se encuentran en los países de la región andino-amazónica, entre los que pueden mencionarse el gas de Bolivia, el petróleo de Ecuador, el agua, la biodiversidad y los recursos forestales de Colombia y Brasil y todo aquello que sea 
Washington e Bogotá, sob a ótica colombiana, verificam-se potencialidades relevantes que condicionaram um reposicionamento securitário do país na correlação de forças regionais.

\begin{abstract}
Hoy puede apreciarse con claridad que entre uno de los objetivos del plan Colombia estaba el de fortalecer la capacidad bélica del Estado colombiano, no sólo para enfrentar al movimiento insurgente sino también para contar con uno de los ejércitos mejor armados del continente, como lo es en la actualidad. Eso se puede mostrar con unos pocos datos, de por sí muy reveladores:

Entre 1998 y 2008, unos 72.000 militares y policías de Colombia fueron adiestrados por personal de los Estados Unidos, lo que hace que Colombia sea el segundo país del mundo, después de Corea del Sur, en recibir este tipo de entrenamiento; a fines de la primera década del siglo XXI se encontraban operando en territorio colombiano 1.400 militares y contratistas (un eufemismo de mercenarios) de los Estados Unidos, cuando a comienzos del Plan Colombia se había dicho que solamente iban a operar unos 400 (PARADA, 2010 apud CANTOR, 2012, p. 381).
\end{abstract}

A evolução da cooperação com Washington, assim, cristalizou-se no aumento de militares, policiais e pessoal atrelado a todo um aparato de segurança que operacionalizou a modernização das forças colombianas. ${ }^{11}$ Paralelo ao fortalecimento dissuasório do país nesse novo cenário, deve-se assinalar o recente crescimento econômico do país, visto com muito bons olhos pelas instituições financeiras internacionais e transnacionais, favorecidas pelo processo de abertura econômica nacional, tornando a Colômbia um dos principais receptores de investimentos externos. 12 Dessa forma, torna-se claro que distintos objetivos permearam o desenho estratégico colombiano transcendendo a operacionalização do Plano Colômbia. 0 que para muitos constitui-se uma fonte de críticas decorrentes de seu papel subserviente a Washington, para Bogotá representou uma escolha pragmática de crescimento do seu poder militar ${ }^{13}$

susceptible de extraerse y mercantilizarse para provecho del imperialismo y sus empresas, como los saberes indígenas de los milenarios habitantes de selvas y bosques de América Central y Sudamérica".

11 Conforme Paley (2015, p. 113): "According to a 2011 report on U.S. cooperation with Colombia prepared by the RAND Corporation and sponsored by the U.S. Air Force, U.S. support for Colombia through the 2000s included the supply of radar systems, helicopter carriers, heavy artillery, surveillance and interdiction training, training for port authorities, advice and equipment for aerial crop spraying programs, and U.S. Special Forces advisers to train the Colombian police and army (Chalk, 2011)".

12 De acordo com Avilés (2008, p. 413), "In addition, the economic policies furthered through Plan Colombia, such as a secure and stable business environment, the liberalization of capital markets and the opening of markets to foreign direct investment, are not simply policies that benefit US-based TNCs, but they represent an economic agenda from which TNCs from around the world can benefit".

13 Benjamín Herrera Chaves (2012 p. 571) ressalva que: "Aunque los términos puedan parecer peyorativos, habrá quienes consideren que la 'subordinación consciente' es una política de Estado y que teniendo en cuenta las debilidades del Estado colombiano o las amenazas del entorno, estar en la órbita inmediata de la política y de los intereses de los Estados Unidos de Norteamérica conlleva un nivel de 
e ampliação de seu desenvolvimento econômico, reinserindo-se nas relações regionais como um país fortalecido.

\section{PERSPECTIVAS DOS DESDOBRAMENTOS DA RELAÇÃO EUA-COLÔMBIA PARA A RECENTE CORRELAÇÃO DE FORÇAS SUL-AMERICANAS}

A cooperação entre Washington e Bogotá via militarização do conflito colombiano evoluiu nos últimos quinze anos, trazendo desdobramentos para as relações entre os países sul-americanos. Desse modo, essa cooperação deve ser analisada à luz do balanço de forças regionais, assentadas nas capacidades dissuasórias e projeção de poder militar entre os países, reverberada pelos objetivos estratégicos traçados para o cenário subcontinental. Distintas abordagens e perspectivas dialogam sobre o papel desempenhado entre esses dois atores para a região, desenhando-se possíveis contornos e alternativas no jogo das relações recentes dos países sul-americanos.

\section{Da dependência à projeção de poder: um novo status colombiano?}

O alinhamento entre Washington e Bogotá alcança um raio de projeção nas relações entre os atores sul-americanos condicionado à estrutura regional e a distribuição de capacidades entre os Estados. A América do Sul, diferentemente de outras regiões, desenvolveu uma dinâmica própria em segurança. O Brasil continua sendo o país sul-americano com maiores recursos de poder, investimento do PIB em defesa, produção energética e com a mais expressiva força aérea e naval da região. Entretanto, o crescimento militar colombiano por meio do recrudescimento de suas Forças Armadas, efetivos, gastos em Defesa e demais contingentes torna-se exponencial para o país na conquista de um novo status frente a seus vizinhos, através de uma análise comparada. Para Bandeira (2008) e Rezende (2013), com a assistência dos EUA, a Colômbia tornou-se o Estado relativamente mais bem equipado da América do Sul (especialmente a partir de 2009), com uma população de 44 milhões de habitantes, a Colômbia adquiriu um contingente militar de 237.466 efetivos, enquanto o Brasil, com

seguridad del cual se carecería en circunstancias de una mayor muestra de autonomia". Dessa forma, a Colômbia persegue uma estratégia pragmática de subordinação consciente aos EUA, continuando a auferir consideráveis vantagens dessa histórica relação. 
8,5 milhões de quilômetros quadrados e mais de 200 milhões de habitantes, possui um contingente de 190.000. ${ }^{14}$

Tabela 1. Capacidades Materiais da Potência Regional e das Potências Secundárias (2013)

\begin{tabular}{|c|c|c|c|c|c|}
\hline $\begin{array}{c}\text { Capacidades } \\
\text { materiais }\end{array}$ & Argentina & Brasil & Chile & Colômbia & Venezuela \\
\hline Orçamento de Defesa & 4511 & 31,456 & 5435 & 13,003 & 5313 \\
$\begin{array}{c}\text { Produção de petróleo } \\
\text { (1000 barris por dia) }\end{array}$ & 707.91 & 2693.86 & 16.07 & 1028.47 & 2689.24 \\
PIB (US\$M) & 609,889 & $2,245,673$ & 277,199 & 378,415 & 438,284 \\
\hline
\end{tabular}

Elaborado pelo autor

Sources: Military expenditure (SIPRI, 2014), Oil Production (EIA, 2014), GDP (World Bank, 2014).

A Colômbia através de sua modernização securitária e o aumento da projeção de poder militar no processo recente obtém maiores potencialidades de atuar assertivamente no "tabuleiro sul-americano", implicando na correlação de forças regionais em uma nova distribuição de capacidades. De um Estado praticamente falido, a Colômbia reinsere-se na arquitetura regional como um país portador de maiores potencialidades de influir na condução de seus objetivos, apesar dos desafios internos remanescentes.

\section{Visões das consequências sul-americanas do alinhamento EUA-Colômbia}

Bandeira (2008) desenvolve uma interessante perspectiva sobre o alinhamento Washington-Bogotá e seus condicionantes para a correlação de forças regionais. Segundo o autor:

\footnotetext{
14 Rezende (2013), porém, defende que um exercício comparativo da Colômbia com o Brasil (a potência regional), o último ainda detém as maiores capacidades de poder militar e o poder latente, sejam em seus gigantes recursos naturais, populacionais, PIB, gastos em defesa, efetivos em Forças Armadas, Marinha, Aeronáutica e etc. Destacaram-se os efetivos nos exércitos com o intuito de elucidar um exemplo do crescimento das capacidades securitárias colombianas no processo recente, não se devendo incorrer uma leitura errônea acerca de seu poder militar ao ser mensurado com demais atores sul-americanos. Também cabe-se acrescentar que grande parte das forças militares colombianas ainda estão voltadas para a contra insurgência (e processo corrente de utilização da força e de rearmamento) e não para uma competição convencional interestatal. Entretanto, o aumento dos recursos dissuasórios do país é irrefutável, em um quadro de modernização e crescimento de seu poder militar.
} 
[...] o objetivo estratégico imediato dos Estados Unidos é armar e mover a Colômbia como importante peça no xadrez da América do Sul. É fazê-la um pivot country, um enclave, como Israel no Oriente Médio, e empregá-la como contrapeso da Venezuela, para qualquer eventual contingência, i. e., de intervenção militar, mas sem usar suas próprias tropas e sim contingentes de um país sul-americano[...]. (p. 26)

Assim, a estratégia estadunidense de preservação de seus interesses regionais consiste na terceirização para o seu parceiro de uma eventual ofensiva militar com governos antagônicos a suas aspirações, como o venezuelano. Essa concepção encontra coro com Cantor (2012), ao demonstrar que os EUA exercem uma influência desestabilizadora na região andina, utilizando a Colômbia como um Estado pivô para antagonizar a Venezuela, Equador e Bolívia. ${ }^{15}$ De acordo com Cantor (2012, p. 396-397), "el gobierno de Estados Unidos pretende mantenerse al margen para dar la impresión que no está involucrado, recurriendo a gobiernos títeres, como el de Colombia, para adelantar todas las acciones criminales de saboteo y desestabilización interna en los países que han adoptado proyectos revolucionarios o nacionalistas". ${ }^{16}$ Assim, por meio dessa perspectiva, as relações EUA-Colômbia representam uma correlação de forças desfavorável aos países andinos, como resultado da propagação da influência estadunidense.

Na visão de Bandeira (2008) também se insere a estratégia da Geopolítica do Cerco, implementada pelos EUA na região, por meio de acordos bilaterais com seus parceiros sul-americanos, além da Colômbia. De acordo com essa leitura, as bases militares e centros operacionais estadunidenses em países como Colômbia, Peru,

15 Em 2008, a Colômbia de Uribe protagonizou atritos diplomáticos com o Equador e a Venezuela, escalando o quadro de tensões, especialmente após um ataque colombiano em território equatoriano sob a justificativa da conivência do país com as FARCs. Ventos de guerra sopraram a região, com reais possibilidades de uma guerra colombo-estadunidense contra a Venezuela de Chávez. A doutrina de Guerra Preventiva (pre-emptive war) havia sido implementada, fazendo a Venezuela mobilizar forças para a sua fronteira. Porém, a ação concertada dos países sul-americanos, sob a liderança brasileira no CDS e da UNASUL, frearam essas animosidades. (VÁSQUEZ, 2012) (BATTAGLINO, 2012)

${ }^{16}$ Avilés (2008, p. 412) trabalha com esse posicionamento, destacando que: "Finally, Plan Colombia has been analysed as representing the 'imperialist' interests of the US government, to protect Latin American markets, resources and labour for the benefit of US-based corporations (Petras, 2001 ). According to this perspective, Plan Colombia represents one part of a US regional strategy to defeat leftist challenges to its power in Latin America, that is, Hugo Chávez in Venezuela and leftist guerrillas in Colombia, and to control the oil resources of the Andes under the cloak of fighting a 'war on drugs' ( Petras, 2001). Any potential threat to US imperial control over the region's natural resources or challenge to the principle of open markets must be addressed through the repression of a guerrilla insurgency and its peasant supporters. According to this perspective, defending US imperialism is the central aim of Plan Colombia and not counter-narcotics". (grifo meu). 
Guiana, Paraguai, Argentina ${ }^{17}$ e etc. são voltadas para um objetivo mais amplo: cercamento do Brasil (potência regional emergente) atrelado à ampla operacionalidade de intervir em qualquer país da região. Padula (2013) respalda essa leitura ao afirmar que a postura intervencionista desempenhada pelos EUA na região visa o controle dos recursos do hemisfério ocidental, impedindo o surgimento de qualquer potência regional ou uma coligação de países em qualquer processo de integração que conteste o seu domínio. Esse cenário torna-se mais crível na contenção aos projetos brasileiros na região ${ }^{18}$, permitindo dessa forma, a manutenção de sua hegemonia hemisférica. ${ }^{19}$

Outra perspectiva existente acerca dos desdobramentos desse alinhamento para a correlação de forças regionais é o papel de barganha que a Colômbia pode desempenhar no "tabuleiro sul-americano", não estando associada diretamente a uma distensão refratária do processo de integração regional ou da liderança brasileira no subcontinente. Segundo essa visão desenvolvida por Pecequilo (2012), Flemes e Wehner (2012) e trabalhada por Mattos (2013), a Colômbia nos últimos anos sob o governo Santos (de 2010 em diante), vem se aproveitando de sua reinserção nas relações sulamericanas para desempenhar um papel pragmático de obtenção de maiores vantagens. Isto é, de acordo com essa visão, a Colômbia além de sua cooperação com os EUA, colhe vantagens frente a dois projetos distintos que se antagonizam regionalmente, barganhando, de maneira pragmática, maiores benefícios por seu novo status nas relações sul-americanas - inclusive com interlocução com a potência regional, o Brasil.20

\footnotetext{
17 Recentemente.

18 Freando também o avanço chinês no subcontinente.

19 Desse modo, verifica-se uma contraposição de forças assentadas no poder militar dissuasório e na parceria norte-americana com países regionais, principalmente a Colômbia, para minar o projeto de integração regional, contrapondo o MERCOSUL e minando a UNASUL. A estratégia é a mesma implementada historicamente pelos EUA com os "frágeis países do sul": dividir para dominar; isto é, priorizando relações bilaterais com os seus parceiros a fim de inviabilizar uma integração políticoeconômica no subcontinente. Indubitavelmente, essa estratégia constitui-se em uma correlação de força desfavorável para um desenvolvimento regional autônomo através da liderança brasileira. Isto é, em uma perspectiva mais abrangente abarcando a correlação de forças sul-americanas, a cooperação WashigtonBogotá insere-se numa estratégia de contrabalanceamento de uma liderança brasileira e um movimento refratário a um processo mais amplo de integração regional através da fragmentação política da América do Sul, somado a pressão dissuasória colombiana exercida a países andinos antagônicos aos EUA. (PADULA, 2013). (BANDEIRA, 2008). (AVILÉS, 2008). (CANTOR, 2012)
}

20 Ainda com relação à presença militar estadunidense no conflito interno colombiano, Pecequilo (2012) destaca o "endurecimento" das ações mencionadas anteriormente com a transição dos governos George W. Bush e Barack Obama, a partir de 2009. Esse processo, no entanto, começa a ser revertido com a presidência de Juan Manuel Santos na Colômbia, cuja política externa tem se caracterizado por uma abordagem menos diretamente associada à parceria com Washington e mais afeita ao pragmatismo, ao multilateralismo na região e a um contato mais amplo com o Brasil - sem que, com isso, a política de 
Por meio desse enfoque voltado ao multilateralismo pragmático colombiano, as possibilidades de uma correlação de forças tornam-se mais favoráveis e viáveis aos países sul-americanos, atrelado ao processo de integração regional. Essa perspectiva assentada na cooperação multilateral entre a Colômbia e países vizinhos - condicionado por sua aliança com os EUA, não antagoniza completamente a visão de pivot country defendida por Bandeira (2008). Essa confluência pode existir a partir da premissa de que todos os Estados buscam aumentar as suas capacidades e vantagens nas relações que estabelecem com os demais, especialmente sob a ótica estratégica colombiana. A alternativa, após esse novo status da Colômbia no cenário regional é perseguir uma postura relativamente mais autônoma ou continuar priorizando o seu tradicional alinhamento aos Estados Unidos, retardando o desenvolvimento dinâmico regional.

\section{CONCLUSÃo}

Esse estudo procurou demonstrar que diferentes estratégias e desdobramentos regionais permearam as relações entre os Estados Unidos e a Colômbia nesses últimos quinze anos, via implementação e evolução do Plano Colômbia. Analisou-se essa relação sob os elementos subjacentes do discurso oficial, avaliando-se os impactos para a correlação de forças recentes da América do Sul.

Diferentes interesses e potencialidades consolidam a permanência dessa cooperação para os próximos anos, trazendo benefícios tanto para Washington quanto para Bogotá em uma relação pragmática de múltiplos ganhos. Discorreram-se esses elementos à luz das transformações regionais operadas no subcontinente, marcadas pelos dois projetos antagônicos assentados na integração regional e a permanência do domínio hegemônico estadunidense.

Desse modo, esse trabalho visou contribuir aos estudos político-estratégicos recentes da América do Sul, apontando as mudanças relativas na correlação de forças dissuasórias da região com a reinserção colombiana na estrutura securitária e o papel político que pode desempenhar para o desenvolvimento dinâmico regional. Apesar de a Colômbia nesses últimos quinze anos não ter solucionado completamente as complexas

barganha desenvolvida pela Colômbia com relação à posição de liderança brasileira e às possibilidades de uma alternativa de integração pela Aliança do Pacífico ou de opção pelo bandwagoning com os EUA tenha sido abandonada (FLEMES; WEHNER, 2012). Ademais, o uso de bases estadunidenses na Colômbia foi recentemente vetado pelo legislativo colombiano, sugerindo o início de uma inflexão desse processo (PECEQUILO, 2012 apud MATTOS, 2013, p. 56-57, grifo do autor). 
disputas internas (Apesar dos avanços recentes do processo de negociação pacífica entre o governo colombiano e as FARCS ), hipóteses e perspectivas devem continuar sendo traçadas em um possível cenário de maior projeção de seu poder para a região, atrelado aos seus desdobramentos regionais. Ao fim e ao cabo, esse estudo procurou trazer novas contribuições sobre essa estratégica relação, reconhecendo que futuros estudos devem continuar sendo desenvolvidos.

\section{REFERÊNCIAS}

AVILÉS, William. US Intervention in Colombia: The Role of Transnational Relations. Bulletin of Latin American Research, v. 27, n. 3, p. 410-429, 2008

BANDEIRA, Luiz Alberto Moniz. A importância Geopolítica da América do Sul na Estratégia dos Estados Unidos. Revista da Escola Superior de Guerra, v. 24, n. 50, p. 7-35, jul/dez. 2008.

BATTAGLINO, Jorge. Defence in a Post-Hegemonic Regional Agenda: The case of the South American Defence Council. In: P. RIGGIROZZI, D. Tussie (eds.), The Rise of Post-hegemonic Regionalism. Springer Science+Business Media B.V. p. 81-100. 2012.

BORBA, Pedro dos Santos. Segurança na América do Sul. Dossiê Temático, NERINT, n. 1, 2009.

BUELVAS, Eduardo Pastrana; PIÑEROS, Diego Vera. De Uribe a Santos: ¿continuidad o nueva orientación de la política exterior colombiana? In: Colombia: ¿uma potencia em desarrolo? Escenarios y desafios para su política exterior. Fundación Konrad Adenauer. p. 57-80. 2012.

CANTOR, Renan Veja. Colombia y Geopolítica Hoy. v. 12, n. 2, p. 214-547. Jul/dez. 2012.

COSTA, Rogério Santos da. O Mercosul e a integração da América do Sul. In: CEPIK, Marco. América do Sul: Economia e Política da Integração Regional. UFRGS. 2008.

CHAVES, Benjamín Herrera. La región andina y las incidencias geopolíticas en la inserción internacional del Estado colombiano. In: Colombia: ¿uma potencia em desarrolo? Escenarios y desafios para su política exterior. Fundación Konrad Adenauer. p. 565-576. 2012.

EIA, 2014

FLEMES, Daniel; WEHNER, Leslie. Drivers os Strategic Contestation in South America. GIGA Working Papers: Power, Norms and Governance in International Relations, n. 207, out. 2012.

FLEMES, Daniel; CASTRO, Rafael. Institutional Contestation: Colombia in the Pacific Alliance. Bulletin of Latin American Research, v. 35, n. 1, p. 78-92. 2016

IBGE Países. Disponível em:< http://www.ibge.gov.br/paisesat/main frameset.php $>$. Acesso em 07/ 06/ 2015. 
JUNIOR, Augusto Wagner Menezes Teixeira; NOBRE; Fábio Rodrigo Ferreira. Plano Colômbia: Implicações para o Brasil. Tensões Mundiais, p. 265- 284. 2009.

KILLEBREW, Robert; IRVINE, Matthew; GLASER, David. A New U.S.- Colombian Relationship: Transnational Crime and U.S. National Security. Foreign Policy Research Institute by Elsevier. Ltd. 2012. p. 233-248.

MATTOS, F. Agendas de Segurança do Brasil e dos Estados Unidos da América para o entorno estratégico brasileiro. 2013. Trabalho de Conclusão de Curso (Graduação em Relações Internacionais) - Faculdade de Economia, Universidade do Rio Grande do Sul, Porto Alegre, 2013.

MEARSHEIMER, John. J. The Tragedy of Great Power Politics. New York: W.W.W Norton \& Company , 2014.

Military Expenditure (SIPRI, 2014), Oil production (EIA, 2014), GDP (World Bank, 2014), Global Competitiveness Index (Worls Economic Forum, 2014).

PADULA, Raphael. A geopolítica da Bacia do Pacífico e a Integração regional na América do Sul. Rev IU. v. 1, n. 2, p. 30-47. 2013

PALEY, Down. Drug War as Neoliberal Trojan Horse. Latin American Perspectives, Issue 204, v. 42 n. 5, p. 109-132, Sept. 2015.

PECEQUILO, Cristina Soreanu. Introdução às Relações Internacionais: Temas, atores e visões. Petrópolis: Vozes, 2012.

REZENDE, L. Sobe e desce! Explicando a cooperação em defesa na América do Sul: uma teoria realista-ofensiva. 2013. Tese (Doutorado em Estudos Estratégicos Internacionais) - Faculdade de Economia, Universidade do Rio Grande do Sul, Porto Alegre, 2013.

ROJAS, Diana Marcela. El taller del império global: Anális de la intervención de Estados Unidos em Colombia (1998-2008). Análisis político. n.65, Bogotá, p.111-126, jan/abr. 2009.

ROSE, G. (1998). Neoclassical Realism and Theories of Foreign Policy. World Politics, 51, 1, 144-172.

SANTOS, Marcelo. Passado e presente nas relações Colômbia-Estados Unidos: a estratégia de internacionalização do conflito armado colombiano e as diretrizes da política externa norte-americana. Ver. Bras. Polít. Int. n. 53, p. 67-88. 2010.

SIPRI, 2014.

VILLA, Rafael Duarte; OSTOS, Maria Del Pilar. As relações Colômbia, países vizinhos e Estados Unidos: visões em torno da agenda de segurança. Ver. Bras. Polít. Int. 48 (2): 86110. 2005.

World Bank, 2014 